\title{
Gênero e Etnografia: reflexões desde algumas prisões brasileiras*
}

\author{
Laura Ordóñez-Vargas**
}

\begin{abstract}
Resumo
O objetivo deste artigo é analisar como o gênero, enquanto tecnologia de poder e em articulação com outras categorias de diferenciação, opera em três dimensões e escalas heterogêneas nas prisões e no fazer etnográfico nesse campo. Na primeira, analiso as formas como gênero constitui a instituição penitenciária. Depois, exploro como gênero atravessa $e$ articula as inserções e a produção do campo etnográfico. Por fim, examino as maneiras como gênero opera enquanto dispositivo de agência e resistência entre a população carcerária.
\end{abstract}

Palavras-chave: Etnografia em Prisões, Tecnologias de Gênero, Prisões Brasileiras.

* Recebido em 18 de março de 2019, aceito em 20 de outubro de 2019.

** Professora de Antropologia, Universidad del Rosario, Escuela de Ciencias Humanas, Bogotá, Colômbia. laura.ordonez@urosario.edu.co / https://orcid.org/0000-0002-0755-0158 
Ethnography and Gender: Reflections from within Some Brazilian Prisons

\begin{abstract}
The aim of this paper is to analyze the ways in which gender as a technology of power (articulated with other categories of differentiation) operates in three dimensions in relation to prisons and in ethnographic doing in prisons. First, in the ways in which gender technologies constitute the penitentiary institution, evident in the strongly gendered masculine character of state punishment. Second, in the ways in which gender devices traverse and produce the ethnographic field. Finally, gender operates in prisons as agency and resistance devices among the inmate population.
\end{abstract}

Keywords: Prison Ethnography, Brazilian Prisons, Gender Devices. 


\section{Introdução}

Quando me lembro de todas as prisões em que já entrei, o primeiro que vem à memória é o barulho de cada abrir e fechar de portas, grades e cadeados sinalizando o caminho de acesso ao seu interior. Intimamente associado com ele, está o cheiro da prisão, forte e penetrante, tão particular quanto o cheiro dos hospitais; só entrando em uma prisão para sentir como ele se impregna na pele e na memória das pessoas que a habitam e que delas entram e saem (Mallart, 2014; Padovani, 2015).

Outra lembrança que resiste ao tempo é a de transitar pelos corredores das carceragens pela primeira vez. Tornar-me alvo dos múltiplos olhares - curiosos, desconfiados ou indiferentes - ao mesmo tempo em que homens e mulheres em cumprimento de penas privativas de liberdade, também se tornavam alvo do meu olhar. Entrar em uma prisão pela primeira vez, como em qualquer campo etnográfico (Wagner, 2010), significa responder aos anseios das pessoas que querem saber quem é você e o que está fazendo ali. Desde agentes penitenciários nas portarias das entradas das instituições, aos funcionários e técnicos e, principalmente, as pessoas presas. Para esses últimos, talvez a primeira coisa que lhes interessa saber é se você pode ajudar de alguma forma na sua situação jurídica. Explicar que você não é advogado, jornalista, nem assistente social ou policial, e sim antropóloga, que não tem competência para ajudá-los legalmente, além de explicar em termos simples o que é a antropologia, e, para piorar, que você fará uma pesquisa etnográfica sobre a prisão, em princípio, não é das tarefa mais fáceis de realizar (Padovani, 2015b).

Nas páginas que seguem, o objetivo é analisar sobre gênero e etnografia desde as prisões. Examino alguns elementos trazidos pelas etnografias em prisões para pensar sobre o fazer etnográfico; bem como algumas questões suscitadas pelo campo das prisões as quais permitem (re)pensar relações de gênero. Para tanto, parto da minha experiência de campo em algumas instituições prisionais femininas e masculinas brasileiras entre 2004 e 2011. 
O primeiro trabalho de campo foi entre 2004 e 2005, na Penitenciaria Feminina do Distrito Federal, Brasília ou "Colmeia", inscrita numa pesquisa mais ampla sobre o papel da religiáo dentro desta instituição. A segunda experiência de campo em contextos prisionais foi entre 2006 e 2008, durante uma pesquisa que tratou sobre a excessiva medicação de droga psiquiátrica dentro de duas prisões femininas: Penitenciária Industrial Estevão Pinto (PIEP), conhecida como "Casa das Barbies", localizada no centro de Belo Horizonte; e, no Presídio Feminino José Abranches Gonçalves (PJAG), também conhecido como o "Furacão", localizado em Ribeirão das Neves, região metropolitana de Belo Horizonte, Minas Gerais.

Posteriormente, realizei trabalho de campo em duas prisões sob o modelo de gestão carcerária APACs (Associações de Proteção e Assistência aos Condenados), entre 2007 e 2009. O trabalho foi realizado em duas APACs masculinas de Minas Gerais, na cidade de Santa Luzia e na APAC masculina de Itaúna, cidade do interior do mesmo estado. As APACs são uma experiência institucional religiosa (de matriz cristã), no campo da política penitenciária brasileira que hoje se replicam no Estado de Minas Gerais, cuja proposta normativa institucional se inscreve pelas noções de "recuperação e humanização dos presos e da vida intramuros". As prisões geridas sob esse modelo de gestão carcerária público/comunitário, se apresentam como um exemplo de cumprimento das legislações e regulamentos relativos à execução penal, conforme o cumprimento das normativas nacionais $e$ internacionais no tocante aos direitos mínimos $e$ tratamento das pessoas privadas da liberdade. ${ }^{1}$ Paradoxalmente, às APACs são reiteradamente outorgadas o adjetivo de prisões alternativas. ${ }^{2}$ Nesta pesquisa, o objetivo foi analisar os dispositivos

1 Como a Lei de Execução Penal de 1984 e as Regras Mínimas para Tratamento dos Presos - adotadas pelo Primeiro Congresso das Nações Unidas sobre a Prevenção do Crime e do Tratamento de Infratores, Genebra, 1995.

2 Também porque apresentam outras características que as das prisões do sistema dominante como: o despoliciamento do espaço prisional, a segurança nas mãos de agentes não armados e dos presos/as, a municipalização da pena, o 
e mecanismos onde se realoca o poder numa prisão de segurança mínima, sem agentes armados, nem arames farpados, bem como, a configuração de novas formas de produção de controle social penal (Ordoñez, 2011).

Cada experiência de campo dentro das respectivas prisões teve objetivos de indagação e ênfases distintos, que certamente afetou e configurou de diversas formas a inserção e a produção do campo. Pode-se notar também que, o trabalho de campo ocorreu em prisões não hegemonicamente tomadas como objeto de análise pela produção de saber sobre prisões nas ciências sociais (femininas e as APACs), o que resulta interessante considerando que, o olhar esteve dirigido para o que não está na centralidade do castigo estatal (prisões masculinas) e, por meio desse olhar constatar que, toda estrutura do sistema penitenciário está marcada pelo gênero. As formas como se nomeiam e representam as cadeias femininas, "Colmeia", "Casa das Barbies" e "Furacão", oferecem as primeiras chaves para inferir isso.

Com relação ao tempo transcorrido entre o campo etnográfico e a escrita deste documento, retomo Strathern (2014). A autora argumenta que a etnografia é feita no trabalho do tempo entre o campo e a escrita do campo, o qual se atualiza em cada nova forma de interrogá-lo, abordá-lo, analisá-lo e representá-lo. Se pensarmos o fazer etnográfico como uma forma de ser e estar no mundo (Peirano, 2014), é quase impossível delimitar o trabalho etnográfico e saber precisamente onde ele começa e onde termina, bem como sua extensão no tempo e no espaço (Gomez Pereira; Yoshie Matsue, 2017).

Com base na experiência de campo nessas prisões e em um olhar retrospectivo, proponho a presente análise desde a categoria "tecnologias de gênero" cunhada por Lauretis (1994). Para ela, a construção de gênero é o produto e o processo, tanto das

envolvimento das famílias dos condenados e das pessoas da comunidade na execução das penas. Para informação institucional sobre as APACs pode-se consultar em: http://www.fbac.org.br/ 
representações como das auto- representações ${ }^{3}$ produzidas nos sujeitos pelas práticas, discursos, epistemologias e instituições dedicados à produção de homens e mulheres (Lauretis, 1994). Em diálogo crítico com Foucault ${ }^{4}$, gênero como tecnologia de poder ${ }^{5}$ opera como (re)produtor e regulador da vida social e subjetiva das pessoas, estrutura as relações sociais e gera efeitos concretos na vida material e nas relações.

É a partir das tecnologias de gênero que proponho retomar meu campo etnográfico nas prisões e voltar a indagá-lo. $\mathrm{O}$ objetivo deste artigo é o de analisar as formas como gênero (na articulação com outras categorias de diferenciação) opera em três dimensões ou níveis na relação entre prisões e o fazer etnográfico. Num primeiro momento, apresento as maneiras como as tecnologias de gênero produzem e constituem a instituição penitenciaria, evidentes no caráter fortemente generificado como masculino do castigo estatal. Na segunda parte, exploro como as tecnologias de gênero atravessam e produzem o campo etnográfico (acesso, trânsitos, relações, posições, vínculos institucionais e situações do campo). Por fim, analiso a operacionalidade da categoria gênero nas micropolíticas da vida cotidiana e enquanto auto-representação. Categoria acionada, portanto, como dispositivo de resistência e agência pela população carcerária.

3 "A representação social de gênero afeta sua construção subjetiva e vice-versa, a representação subjetiva de gênero (auto-representação) afeta a construção social" (Lauretis, 1994:217).

4 Ainda que a autora estabeleça a analogia com o dispositivo de sexualidade de Foucault, se distancia da sua postura e critica os modos como na sua teoria ele não considera os apelos diferenciados dos sujeitos masculinos nem femininos $e$ ignora os conflitos entre homens e mulheres nos discursos $e$ nas práticas de sexualidade (Lauretis, 1994).

5 Tecnologias de poder definidos como os procedimentos, estratégias, atos, tácticas, simbolismos, manobras que operam de maneira capilar e microfísica, através das quais se configuram e se exercem as relações de poder (Foucault, 2003). 
A escolha dessa categoria como central responde a várias questóes amplamente problematizadas por diversas produções feministas. Dentre essas, porque as tecnologias de gênero contemplam dispositivos heterogêneos e variáveis que operam em escalas diversas, tanto nos níveis macro (governo das populações) como nas microfísicas do poder, abrangendo o amplo espectro da sua operatividade (Amigot; Pujal, 2009). Ao mesmo tempo, porque a categoria permite compreender o gênero na sua intersecção com outros atributos que produzem diferenciações e desigualdades sociais, tais como raça, classe, nacionalidade, religião, sem os quais seria impossível entende-lo. Ao considerar as diferenças entre os sujeitos e posições no mundo social, a categoria também pondera as experiências, efeitos e relações de poder/resistência específicas marcadas pelo gênero e suas interseccionalidades. Nesse sentido, "gênero como categoria analítica" resulta útil e com grande potencial para tentar desentranhar a inteligibilidade das relações de poder e suas polimorfas configurações nas relações sociais contemporâneas (Amigot; Pujal, 2009).

\section{Gênero na produção do castigo estatal e das instituições prisionais}

As instituições prisionais como parte do aparelho de dispositivos estatais de segurança e de governo das populações e como processos de Estado (re)produzem representações de gênero, que, por sua vez, (re)produzem processos de Estado numa relação de mútua constituição e coprodução entre ambos (gênero e Estado) (Vianna; Lowenkron, 2017). Nesse sentido, as prisões refletem o duplo fazer entre gênero e estado.

Gênero, como argumentou Davis (2018), é o dispositivo por meio do qual a própria noção de crime se produz como masculina (negra, pobre, jovem), normalizando a ideia de que as instituições penais masculinas são a regra. Dito de outro modo, as instituições prisionais são produzidas pela gramática normativa de gênero (Butler, 2003), por marcações e categorias de masculinidade, que refratam $e$ (re)produzem tecnologias de poder. 
A centralidade do gênero na produção e compreensão do castigo estatal tem suas raízes históricas no surgimento $e$ consolidação da prisão como castigo moderno. Enquanto homens com comportamentos desviantes foram definidos como criminosos, as mulheres desviantes foram representadas como loucas/insanas (Almeda; Di Nella, 2017; Lagarde, 2006) ou, de acordo com Aniyar de Castro (2002), agressoras, pecadoras sexuais, bruxas, bêbadas, de vida fácil ou desobedientes.

O surgimento das prisões femininas no Brasil são exemplo disso. Assim, elas foram inauguradas em 1924 como espaços de reclusão explicitamente moralizantes dirigidos a corrigir a natureza viciada e contaminadora das mulheres, julgadas por delitos menores e relacionados com o controle do seu comportamento, corpo e sexualidade, tais como a vadiagem, o infanticídio, o aborto, embriaguez, desocupação, entre outros (Musumueci; Ilgenfritz, 2002; Andrade, 2011). As prisões, portanto, têm se configurado como as instituições dominantes para o controle do crime masculino, enquanto hospitais psiquiátricos e manicômios têm desempenhado o mesmo papel na reforma da insanidade feminina, geralmente sexualizada e racializada (Davar, 2001; Davis, 2018). A continuidade da representação socialmente categorizada como feminina da insanidade/criminalidade permanece até hoje nas prisões de mulheres, onde as drogas psiquiátricas continuam a ser distribuídas muito mais extensivamente às mulheres do que aos homens presos (Davis, 2017).

O caráter generificado do castigo estatal também se expressa em condenações mais altas para as mulheres em relação aos homens pelos mesmos delitos; nas assistências penais que desconsideram as particularidades e necessidades das mulheres na mesma situação, na precariedade dos espaços físicos dos estabelecimentos penais femininos (Ministério da Justiça, 2014; Almeda, 2017). Acrescenta-se à superlotação, as deficientes condições de salubridade, o permanente tempo de inatividade e a violação sistemática de seus direitos (saúde, estudo, trabalho, assistência legal), situações que traduzem a escassez de políticas 
públicas específicas para mulheres presas (Anthony, 2007; Almeda, 2017).

$\mathrm{O}$ aumento vertiginoso do encarceramento de mulheres no Brasil e na América Latina, associado a política de drogas (60\%) (WOLA et. Al, 2016), reflete a vigência dos efeitos marcados por gênero do castigo estatal. No caso específico do Brasil, no ano 2000 havia 5.601 mulheres em medida de privação de liberdade e, em 2016, esse número subiu para 44.721, representando um aumento de 698\% em 16 anos.

Com isso, quero ressaltar como as tecnologias de gênero operam na realidade concreta das prisões femininas sobre representada por mulheres não brancas $e$ pobres, alvos da criminalização e processos de aprisionamento (Alves, 2017). A continuidade histórica e estrutural de raça e gênero nas paisagens prisionais contemporâneas $e$ as formas como tem evoluído em escala, urgência e complexidade (Drake; Earle; Sloan, 2015), situam as prisões como as instituições que mais contribuem para a segregação e marginalização social das mulheres negras e pobres (Davis, 2017). O caráter fortemente generificado da punição, ao mesmo tempo, reflete e aprofunda a estrutura generificada da sociedade mais ampla" (Davis, 2017:72).

\section{Gênero na produção do campo etnográfico em prisões}

O campo etnográfico, seguindo a Clifford (1999), é uma prática espacial e temporal, corporizada e situada que ocorre a partir de um encontro profundo, intenso $e$ interativo com as pessoas do grupo estudado (Clifford, 1999). O campo é produzido na e pela "zona de contato"6 (Pratt,1991) entre o pesquisador e os

\footnotetext{
6 As zonas de contato referem-se aos espaços sociais dos encontros culturais em que os indivíduos separados por geografia e história entram em contato ente si, inscrito em marcos de relações de poder assimétricas como o colonialismo e a escravidão (Pratt, 1991). Metodológica e epistemologicamente o conceito resulta útil para pensar a pesquisa etnográfica desde o lugar da zona de contato. $\mathrm{Na}$ geopolítica do conhecimento, no meu caso, a zona de contato ocorre entre uma pesquisadora do sul estudando um contexto no sul.
} 
pesquisados, é produzido nos encontros (e desencontros) entre subjetividades (pesquisados e pesquisador) histórica, cultural $e$ socialmente localizadas em termos de gênero, raça, classe, nacionalidade, e é isso o que mostrarei a seguir: como gênero, na interseção com outras categorias de diferenciação, foram centrais na zona de contato e na produção do trabalho de campo etnográfico nas prisões femininas e masculinas brasileiras referidas acima.

Em um meio pautado por relações de poder e controle explicitas e englobantes, o acesso às prisões foi o primeiro desafio que teve de atravessar para conseguir empreender às pesquisas. É difícil obter acesso sem barreiras, nem filtros burocráticos, somado ao tempo que se deve esperar para obtê-lo (Rhodes, 2001; Wacquant, 2002; Waldram, 2009). Para poder aceder às prisões femininas tive de solicitar a autorização do juiz de execuções criminais, depois esperar a aceitação das diretoras das respetivas instituições penais e das diretoras das respectivas dependências (ressocialização, de saúde, das agentes penitenciárias), para poder enfim, estabelecer contato e relação com as mulheres presas.

$\mathrm{Na}$ segunda vez que tentei ingressar na Penitenciária Feminina de Brasilia, a "Colmeia", para realizar a pesquisa sobre o uso e distribuição de medicamentos psiquiátricos na unidade, a Diretora da penitenciária negou o ingresso mesmo mediante prévia autorização judiciária. Pouco depois, contudo, ela teve de acatar a ordem do juiz corregedor, uma autoridade superior a ela. Mas os trânsitos pelos espaços e relações da cadeia ficaram comprometidos à vontade da Diretora e da equipe de disciplina da prisão que, por meio de recursos capilares de gestão e governo das relações na instituição prisional, impuseram impedimentos para a continuidade da pesquisa nessa instituição.

Disso resultou a troca do campo etnográfico da Colmeia, em Brasília, para a Casa das Barbies, em Minas Gerais. Foi, afinal, por meio da negativa ou das dificuldades encontradas para realização do trabalho de campo no Distrito Federal que eu me aventurei a tocar às portas das prisões femininas de Belo Horizonte. Esse campo foi se abrindo generosamente, mesmo que 
mediados pelos requerimentos e filtros burocráticos próprios desses contextos. Em pouco tempo consegui acesso à Penitenciária Feminina Estevão Pinto (Casa das Barbies) e ao Presidio Jose Abranches Goncalves (Furacão). Já, nas prisões sob os moldes das APACs, pela sua explicita porosidade em relação ao "mundo de fora" (Ramalho, 1979), foi muito mais fácil e rápido o acesso. No dia que cheguei a Itaúna pela primeira vez, consegui ingressar às instalações $e$ inclusive almoçar $e$ conversar com os que cumpriam pena privativa de liberdade ali.

A representação clássica de Goffman (1961) sobre as prisões como "instituições totais", que cristaliza a ideia de espaços fechados, estáticos e autocontidos, foi contestada desde o primeiro dia que entrei numa prisão. Essas têm uma vida e dinâmica intramural própria circunscrita e bem delimitada para todos seus atores, mas também estão constituídas e instituídas nas suas múltiplas relações com o fora, a partir de um emaranhado de fluxos, trânsitos e intercâmbios entre o "mundão" e a prisão (pessoas, objetos, afetos), âmbitos sistematicamente conectados pelas mesmas divisas que os separam (Godoi, 2010).

Uma vez superada a questão burocrática do acesso às instituições prisionais, os trânsitos e a circulação pelos espaços físicos intramuros são outra constante com a que os pesquisadores devem lidar, diferente de outros contextos que não apresentam restrições de tempo e espaço. Nos contextos prisionais femininos, a mobilidade pelos diversos espaços e o acesso às mulheres presas apresentavam uma série de condições, além do fato de que minha circulação lá dentro requeria certa logística como, disponibilizar algum espaço e o tempo de alguma agente penitenciária durante as visitas. Assim, para conseguir chegar até as mulheres que cumpriam pena e conversar com elas, havia que se relacionar primeiro com os diversos funcionários que compõem a prisão. Nas APACs tive um maior trânsito em comparação com o que tive nas prisões femininas, o que não significou menos vigilância e controle sobre mim. Nesse sentido, a vigilância institucional explícita, sob o argumento de velar pela minha "segurança" $e$ integridade, bem como a aguda vigilância por parte da população presa sobre 
minha presença e sobre minhas formas de agir dentro dos pavilhões e dos espaços de convívio, também particularizam a experiência e a produção do trabalho de campo em prisões.

Além desses elementos, o trabalho de campo etnográfico também esteve atravessado pelas "zonas de contato", pelos lugares de enunciação dos diversos atores prisionais e dos meus (em termos de gênero, raça, nacionalidade), pelas múltiplas $e$ dinâmicas relações $e$ posições que se configuram durante o campo, pelas tensões e negociações constantes com os atores e as situações de pesquisa (Earle, 2015).

Nas prisões em que atuei como pesquisadora/antropóloga, bem como no contexto brasileiro e latino americano, de maneira geral, o perfil sociodemográfico das pessoas privadas da liberdade continua sendo conformado por homens e mulheres jovens (entre 18 e 35 anos), não brancos, pobres e com baixos níveis de escolaridade e ocupação. No caso das mulheres, soma-se a condição de mães solteiras chefes de família (80\%) (Ministério da Justiça e do Direito, 2017; WOLA et. Al, 2016).

Com relação a mim, como pesquisadora, havia também, algumas características que me localizavam frente aos diversos interlocutores no estabelecimento das relações em campo, tais como: mulher (casada e, posteriormente, grávida), estrangeira/ colombiana (hispano-falante), antropóloga (pesquisadora).

Em decorrência das nossas nacionalidades distintas, meus interlocutores/as brasileiros/as e eu colombiana, a língua sempre foi a primeira e onipresente marca dos nossos encontros e do estabelecimento das relações em campo, atuando como um dispositivo que me situou de uma forma muito particular nesses contextos. Enquanto as pessoas presas falavam "português de rua", eu falava "português com sotaque carregado". Apesar dos ruídos gerados pela língua, no entanto, todas as pessoas, desde os agentes penitenciários nas portarias, até as pessoas presas com as quais conversei manifestavam reiterativamente seu gosto pelo espanhol ou pelo sotaque.

Nas prisões, não era somente uma estrangeira que falava espanhol, era colombiana e isso, irônica e excepcionalmente, me 
posicionou positivamente frente aos presos e presas. Ser colombiana no Brasil e em diversos lugares do mundo, carrega uma marca no imaginário social associada quase que automaticamente com: narcotráfico, cocaína, Pablo Escobar ou as FARC. A estereotipação dos colombianos sob esses rótulos abriume, nos contextos prisionais várias portas, e me fez depositária de certa empatia e cumplicidade por parte dos atores prisionais. Se eu era colombiana, entendia e conhecia o "mundo do crime" (Ramalho, 1979; Feltran, 2011) e essa condição me outorgou uma posição que me autorizava entrar e explorar aquele lugar $e$ aquelas pessoas.

Uma mulher em cumprimento de pena, assim, quando me ouviu, reconheceu pelo sotaque que falava espanhol e me disse: "De donde eres", ao que respondi que da Colômbia. Ao que a mulher afirmou quase gritando: "iAdoro os malandros colombianos, são os melhores para fazer roubos, documentos falsos, dinheiro falso, são os melhores mesmo!"7. Pediu que a entrevistasse para conversar "sobre vários assuntos", pedido que aceitei de imediato. Teve outro dia que estava na APAC de Santa Luzia e disse aos presos e plantonistas que durante dezembro não visitaria a prisão porque viajaria para Colômbia, ao que me responderam rindo: "não esqueça de trazer pra nós aquele "pozinho" branco (cocaína) de vocês que é tão bom" eles, também rindo, que ia trazer sim, mas não o pó branquinho e sim o marrom que também cheira muito bom, referindo-me ao café. Esses, como outros eventos cotidianos, exemplificam as formas como a "colombianidade" me colocou em certos lugares que permitiram certos trânsitos pelas pessoas dentro das cadeias.

7 Diário de campo, PIEP, nov./2006.

8 Diário de campo, APAC Santa Luzia, fev./2008.

9 Adriana Piscitelli no seu artigo "Sexo tropical em um país europeu: migração de brasileiras para a Itália no marco do "turismo sexual" internacional" (2007), trabalha a categoria "brasilidade". Me inspiro na autora para fazer as ponderações sobre "colombianidade" aqui. 
Minhas entradas nas penitenciarias femininas e nas APACs deram-se sempre sob o mesmo registro de estatuto relacional com a prisão, isto é, como pesquisadora, o que também me posicionou de formas particulares dentro dos contextos prisionais. Padovani (2017), ao analisar os dispositivos de segurança e gênero nos processos de produção das "classes perigosas", através das portarias da entrada às instituições prisionais, explica isto melhor. A partir dos diversos vínculos que ela estabeleceu com as prisões femininas (paulistas e catalãs) dentro das quais realizou suas pesquisas, isto é, como: voluntaria da pastoral, familia/visita $e$ pesquisadora, a autora relata a exigência institucional respeito à definição da sua relação com a prisão, necessária para estabelecer os rituais de exame a serem praticados sobre ela nas portarias das entradas.

Quando ingressava sob o vínculo de pesquisadora, Padovani (2017:39) relata como foi "enredada em determinadas relações com a universidade e com o canônico campo da pesquisa masculina, por tanto, feminizada e embranquecida, que a situavam numa classe média a ser protegida". Quando ingressava como visita de algumas mulheres presas, que a incluíram na lista devido aos fortes laços de amizade construídos durante o campo, $e$ que a vincularam de outras maneiras com as prisões, analisa como esse mesmo corpo foi enegrecido e produzido como perigoso pelo aparelho de segurança do Estado, materializado no procedimento vexatório da revista íntima.

Nas minhas inserções, ao ingressar como pesquisadora não representava perigo, mais bem fui situada sob a égide institucional que me protegia das "classes perigosas", exemplificando como as relações de poder são emaranhadas pelos atributos de gênero, raça e classe que os produzem e que produziram meu estatuto relacional com a prisão, bem como o de toda pessoa que ingressa às prisões.

O fato de ser mulher cisgênero, colombiana, acadêmica, branca (ou não, mas sim racializada na relação com a prisão), localizada a partir desses atributos e identidades sociais das mais diversas formas pelos diversos atores, operaram de maneiras 
particulares quando associadas com o fato de estudar uma população carcerária feminina ou masculina, bem como, ser uma antropóloga e não um antropólogo fazendo pesquisa. No caso da realização de campo em prisões femininas, o denominador comum de sermos mulheres pautou o estabelecimento de relações próximas e íntimas que se manifestaram nas perguntas que foram realizadas, nos temas das conversações, na abertura mutua, no conteúdo dos nossos relatos e nas cumplicidades que foram se tecendo entre nós em cada encontro (Ordóñez-Vargas, 2006; Carr, 2015). Diferentemente, fazer campo em prisões masculinas gerou em mim apreensão e desconfiança em termos da minha segurança pessoal, considerando que estava realizado a pesquisa sozinha $e$ não com uma equipe respaldando e acompanhando as inserções em campo. Contudo, o fato de serem prisões sob os moldes das APACs, permitiu-me superar os temores para ingressar neste universo.

No entanto, fiz questão de me apresentar como uma mulher casada, me colocando de antemão em uma posição que não me fizesse uma mulher disponível, o que não era mentira, mas apelar a minha situação conjugal nesse contexto era realmente importante para mim em relação aos homens que cumpriam pena $e$ às suas mulheres, com as quais eles mantinham contato frequente. Além do fato de serem prisóes masculinas, as APACS são instituições de gestão prisional reconhecidamente cristã $e$ vinculada a organizações religiosas. Mediante esse contexto, apresentar-me como uma mulher que vive com seu companheiro fora do sacramento do matrimônio me deixaria em uma posição desconfortável perante os agentes e funcionários da instituição $e$, talvez, imoral aos olhos de diversos atores da entidade. Desde meu primeiro ingresso na APAC, portanto, fiz uso de uma aliança de casada com o objetivo de simbolizar meu status familiar e, assim, facilitar minha inserção e evitar mal-entendidos e prejuízos que considerei desnecessários.

Além dos respectivos lugares de enunciação que configuraram as relações de múltiplas formas, havia também um conjunto de situações sociais que nos posicionaram (as mulheres 
presas e a mim) das mais diversas formas dentro daquele contexto. Lembro-me de um dia em que uma agente penitenciária me disse, assim que cheguei ao Presídio Jose Abranches Gonçalves: "hoje você vai falar com Ana, pois, o filho dela morreu ontem e não conseguirá comparecer ao enterro. Está precisando desabafar". ${ }^{10}$ De repente, fui colocada por essa agente penitenciária, como psicóloga ou assistente social de uma mãe presa que se encontrava em uma situação extremamente delicada $e$ de profunda dor, que além do mais, foi obrigada a conversar comigo, uma completa estranha, sobre o inenarrável. Trago isso para ressaltar que, não existe uma única posição que os pesquisadores ocupemos e na qual sejamos posicionados durante o curso das pesquisas, mas sim várias posições e status que variam de acordo às circunstâncias sociais que afetam as interações $e$ relações com os diversos atores (Hammersley, 2015) e que produzem as zonas de contato e o próprio campo etnográfico. Desse modo, as diferentes maneiras pelas quais o gênero opera ( $e$, em alguns casos, intencionalmente é capitalizado pelos pesquisadores) sempre terá consequências (Moolman, 2015).

Dentro das possibilidades que tive, procurei constantemente estabelecer algum tipo de reciprocidade com os presos e as presas em troca do tempo e das histórias que eles e elas compartilhavam comigo. Ainda que fosse muito restrita a lista de objetos $e$ materiais com os quais eu podia ingressar, em todas as cadeias que entrei sempre levei cigarros, um bem muito prezado em qualquer prisão. Mas também ingressei livros que deixava nos pavilhões para que circulassem. Nas prisões femininas, me eram pedidas letras de músicas, que eram escritas em uma lista, de modo que eu as levasse na visita seguinte de maneira impressa. As letras eram usadas para inspirar as cartas de amor que escreviam com muito esmero e dedicação.

Parece-me, contudo, que o mais importante que levei para as pessoas privadas da liberdade, homens e mulheres, foram meus ouvidos e os espaços de conversação. Em todos os contextos

${ }^{10}$ Diário de campo, Presídio José Abranches Gonçalves, mar./2007. 
prisionais as mulheres $e$ os homens presos nunca foram um obstáculo na realização do trabalho de campo, sempre demonstraram vontade de se narrar, de conversar sobre si e suas vidas, principalmente, de serem ouvidas. Ao final de contas, eu era alguém duplamente de fora, fora do Brasil e fora da cadeia, que trazia novidade, mas, sobretudo, que estava disposta a escutar e com quem eles e elas podiam "desabafar". Quando chegava aos pavilhões das cadeias, qualquer uma delas, havia sempre alguma pessoa que ali cumpria pena querendo falar comigo. Em repetidas ocasiões, nossas conversações foram abruptamente interrompidas por algum guarda, sinalizando meu horário de saída dos pavilhões, caso contrário, teria podido permanecer durante longas horas conversando tanto com homens como com as mulheres privadas de liberdade pelo Estado.

Nas prisões, não somente os presos estão ávidos por falar, na minha experiência de campo, outros atores como agentes penitenciárias, técnicos e funcionários também o estavam. Dessa forma, a etnografia em prisões se caracterizou por contextos sociais cujos atores, têm uma enorme necessidade de falar, de se narrar e de serem ouvidos. Assim, ainda que a observação da ação, da interação e o convívio cotidiano prolongado mais próximo e espontâneo com homens e mulheres privados da liberdade seja limitado - que sejam apresentadas de maneira constante restrições de tempo e de espaço para a manutenção das relações, dos espaços de fala e de escuta, das zonas de contato -, os discursos e relatos dos seus atores sociais sobre essas ações $e$ interações sempre resultaram extremamente ricos e reveladores. Desse modo, a despeito das opacidades, a realização de pesquisas etnográficas dentro das prisões é extremamente relevante, dentre outras razões, porque através de uma variedade de contextos internacionais e locais faz-se possivel considerar as dimensões sociais e políticas dos usos e das experiências do aprisionamento em diversos lugares do mundo (Drake; Earle; Sloan, 2015:11). 
Gênero como tecnologia de agência e resistência

Depois de mostrar a operatividade das tecnologias de gênero numa dimensão macro, bem como na produção do trabalho de campo etnográfico, a seguir, indago sobre as maneiras como gênero opera também nas micropolíticas da vida intramuros, cujos efeitos ocorrem no nível das subjetividades, das auto-representações e das resistências, refletindo como gênero também é produzido nas margens das representações dominantes, nos trânsitos dos sujeitos presos entre as diversas categorias de identidade e sexualidade.

Se considerarmos que as identidades sociais são realizadas através dos espaços $e$ das tramas das relações de poder que se tecem nos diferentes contextos (Moolman, 2015:200), nas prisões as identidades e a própria sobrevivência estão sujeitas a negociações muito delicadas e tensas (Castilho, 2006). Nesse sentido, masculinidades $e$ feminilidades normativas são postas em tensão $e$ articulação nos emaranhados $e$ nas tramas de poder em prisões femininas e masculinas como mostrou o campo. Isso porque não tem só mulheres nas prisões femininas, mas há também homens trans, do mesmo modo em que, há mulheres trans em prisões masculinas e sujeitos que transitam constantemente entre diversas categorias de identidade, de acordo com a situação, produzindo efeitos relacionais diversos a cada uma de suas escolhas semânticas (Zamboni, 2017:95).

Nas APACs masculinas, por exemplo, emerge uma clara tensão entre duas representações de masculinidade: uma masculinidade violenta (hegemônica nas prisões do "sistema comum"11) e uma masculinidade cristã (exigidas nas APACs). Nas primeiras, a violência institucional não somente é esperada, mas também é constitutiva das relações entre prisioneiros e guardas $e$ dos prisioneiros entre si (Davis; Dent, 2003:530). Privilegiam-se representações de masculinidade onde a violência é seu correlato.

\footnotetext{
${ }^{11}$ Forma como as pessoas privadas da liberdade das APACs se referem às prisões do sistema dominante de prisão.
} 
Nas APACs, pelas características da sua proposta de humanização $e$ recuperação e pelas bases cristãs do modelo de gestão carcerária, as representações de masculinidade que circulam mudam e são tensionadas com a masculinidade dominante do "sistema comum".

Em várias ocasiões e espaços de reflexão destinados aos "recuperandos" (nome dado aos reclusos neste modelo) como cursos, oficinas, palestras, entre outras atividades, apelava-se explicitamente a outras formas de masculinidade atreladas a valores cristãos: esposos, pais de família, trabalhadores honestos, responsáveis e heterossexuais, impondo como regra a transformação dos prisioneiros em direção a uma masculinidade dócil, submissa e não violenta que, certamente, gera tensões $e$ conflitos subjetivos para os presos que vêm do outro sistema. As disputas entre as representações de masculinidade dentro da população carcerária das APACs se traduzem nas tensões $e$ trânsitos dos recuperandos entre os "compromissados com a verdade" e os "omissos".

As APACs propõem um modelo de autogestão, no qual, a vigilância e custodia direta e cotidiana é realizada conjuntamente pelos plantonistas (os quais não são policiais e não estão armados) e pelos próprios recuperandos, por aqueles que pertencem aos Conselhos de Sinceridade e Solidariedade (CSS). A entidade outorga parte do controle, da segurança e da disciplina à população prisional, sob o argumento que afirma que, ao serem os recuperandos os melhores conhecedores das regras e dos códigos do "mundo do crime", são eles os mais aptos para desarticulá-los cotidianamente. Assim, os CSS atuam como órgãos auxiliares da administração da APAC, cuja função é fazer cumprir as determinações institucionais de controle, com base $e$ a favor das regras da entidade.

Nessas figuras e sob essas atribuições, se operacionaliza uma das bases que fundamentam o método: a confiança, cuja maior expressão se manifesta na entrega das chaves dos presídios aos próprios presos que pertencem aos CSS, desestruturando a lógica de funcionamento de qualquer prisão. A rigorosa vigilância 
exercida pelos membros do CSS sobre a população prisional apresenta-se muito mais panóptica que qualquer cadeia do sistema comum, como disse um recuperando, "parece que é o próprio diabo que vigia a gente aqui dentro". ${ }^{12}$

O pertencimento aos CSS ou a adesão explícita ao método APAC significa necessariamente para esses recuperandos "compromissados com a verdade" se posicionarem contra o código de honra prisional. Código que, nas prisões do sistema comum, opera como um mecanismo de manutenção e de controle social que emana da própria população carcerária sobre si mesma, com o objetivo de fixá-la no mundo do crime. Esse código se instaura como um poder paralelo à administração prisional e como um poder dominante entre a população presa.

A inversão de papeis assumida pelos recuperandos que pertencem aos CSS, nas suas palavras, "ladrão trancando ladrão" ou "preso caguetando preso", quebra uma das máximas deste código que é a delação. Delatar, que na linguagem dos presos se diz "caguetar" ou " $x$-noviar", ao ser uma das transgressões mais graves no mundo do crime, é severamente penalizada com a morte dentro ou, posteriormente, fora da prisão. Como disse Wilson, que cumpria pena na APAC durante o período de meu trabalho de campo, "as pessoas que participam do CSS, caso voltem para lá embaixo (prisões do sistema comum), são automaticamente consideradas caguetes. Os companheiros que andavam com ele e que ele caguetou, matam ele". ${ }^{13}$

$\mathrm{O}$ que na APAC significa sinceridade, no código de honra prisional significa delatar, trair, e o método transforma a delação $e$ a traição em comportamentos esperados e premiados. Deste modo, a figura dos CSS introduz uma inflexão no código de honra prisional, e com ele nas representações dominantes de masculinidade a ele associadas, que desarticula as práticas $e$ lógicas do mundo do crime, gerando tensões e reposicionamentos subjetivos dos recuperandos frente a esse outro regime de poder.

\footnotetext{
${ }^{12}$ Entrevista, APAC Santa Luzia, abril /2009.

${ }^{13}$ Entrevista. APAC Itaúna, dez/2007.
} 
Por sua vez, os "omissos", que continuam a se reger pela lei do crime, também se encontram constantemente diante de situações cotidianas que os colocam em dilemas frente a si, a suas ações e relações com os outros recuperandos. Para esses, ter de tratar igual aos recuperandos enquadrados no crime de estupro é uma situação difícil de aceitar e de praticar. Sob o lema da entidade: "Aqui entra o homem e o crime fica de fora", impõe-se o convívio entre os presos, independentemente do tipo de crime praticado, invertendo outra das máximas do código de honra prisional: a convivência com os estupradores, significando outra das maiores transgressões a este código. Nas gírias prisionais, o estuprador é conhecido como "duzentinho", "duzentão" ou "ladrão de pererecas", por corresponder ao artigo 213-214 no Código Penal. Via de regra, no sistema comum, os presos que praticaram esse tipo de crime são encaminhados para o "seguro dos estupradores". Se por ventura um estuprador ficar no convívio, junto com a maioria da população prisional, ele estará condenado a sofrer um estupro coletivo, muitas vezes, seguido da morte. O depoimento de Adrian, um recuperando, expressa o sentir de muitos deles: "Tem muitos artigos (crimes) aqui, que lá na cadeia são condenados por nós como o estupro, mas na APAC 'somos todos irmãos'. Isso é muito difícil. Eles têm que morrer mesmo! Mas na APAC cada um tem que ficar na sua e assegurar a onda". ${ }^{14}$

Para outros recuperandos, como o expressou Milton, a proibição do uso da violência física entre eles, também é considerada como um vetor de tensão muito forte dentro das APACs. Nas suas palavras, "prefiro apanhar ou dar o soco na hora, do que ter que ficar me assegurando. Isso deixa a gente muito nervoso aqui dentro". ${ }^{15}$ Presenciei, em algumas ocasióes, o confronto entre os "omissos" e os "compromissados" com a verdade, assim como a plasticidade e o trânsito dos recuperandos entre ambas as posições. Eis alguns exemplos: Walter, um homem

\footnotetext{
${ }^{14}$ Diário de campo. APAC Itaúna, dez/2007.

${ }^{15}$ Diário de campo. APAC Santa Luzia, nov./2009.
} 
mais velho que ocupava os altos comandos do CSS do regime fechado da APAC de Santa Luzia, gozava da plena confiança da diretoria, dos plantonistas e voluntários. Foi levado para o hospital devido a uma cirurgia na mão que a própria entidade havia tornado possível. Após a cirurgia, durante sua estadia no hospital este recuperando fugiu. Dados seus conhecimentos de enfermagem, ele sabia como fazer os curativos em seus ferimentos provenientes da cirurgia. Quer dizer, Walter usou as regras da instituição não somente para fugir, mas também para fazer uma cirurgia que, de outro modo, teria sido impossível de levar a cabo. Sérgio havia nove anos que estava preso, dos quais os últimos dois na APAC, pertencia ao CSS e cuidava do portão da entrada principal da APAC de Santa Luzia, durante o trabalho de campo. Sérgio, quando se sentiu mais à vontade comigo, confirmou-me que intermediava a entrada de vários objetos e mercadorias consideradas lícitas e ilícitas, pela direção da instituição, para dentro dos espaços de convivência da APAC. Disse, também, que adorava a solidão que sua função requeria, pois, além da tranquilidade trazida pelo fato de estar longe do convívio com os outros recuperandos, podia fumar sua maconha sem que ninguém percebesse, nem o incomodasse. Seu pertencimento ao CSS lhe permitia driblar as normas com maior facilidade.

Como se pode ver, a figura dos CSS introduz uma inflexão no código de honra prisional, que desarticula as práticas e lógicas do mundo do crime, e junto com ele, as representaçóes de masculinidade dominantes das prisões do sistema comum, gerando tensões, trânsitos e reposicionamento subjetivos dos recuperandos frente a esse outro contexto e regime de poder. Ao mesmo tempo, a figura do CSS se configura como um dispositivo panóptico de hipervigilância ao interior da população presa, utilizado pela entidade como um poderoso mecanismo de controle. Esse exemplo resulta interessante porque trata, sobre o trânsito entre dois modelos de masculinidade.

Nas prisões femininas, contudo, feminidades também são postas em tensão. Quando pesquisei o papel da religião dentro da Penitenciária Feminina do Distrito Federal, na "Colmeia", em 
repetidas ocasiões nas conversações com as mulheres reclusas, surgiu o tema dos conflitos entre as relações homossexuais $e$ homoafetivas entre as presas e os discursos e grupos religiosos que circulam no cotidiano prisional. Mesmo com a rejeição explicita por parte desses últimos frente as relações afetivas e sexuais entre as mulheres, essas são bastante frequentes.

Assim, explicaram-me os trânsitos a classificação que faziam entre elas em relação ao gênero $e$ a sexualidade intramuros. Havia: as "entendidas", as "simpatizantes" e as "convertidas". Segundo, Isabela, "a entendida é a pessoa que já vem da rua assim e que é assumida desde antes de ser presa". Dentre as "entendidas" existem outras categorias como, "gayzinha", "veadinhos", "machorras", que representam as reclusas transmasculinas, que utilizam símbolos corporais tais como cabelo curto, jeito de caminhar, de se vestir e de agir como um homem, mas também estão outras categorias como, "bicudo", "dedoduro", "sapatona", que são metáforas da orientação sexual $e$ referem-se às presas que não representam sua identidade de gênero como masculina. As "simpatizantes", continua Isabela, "são as mulheres que têm seu primeiro relacionamento com outra mulher aqui dentro, mas quando possível ficam com homens de fora" ${ }^{16}$ Já as "convertidas" são aquelas mulheres que, do mesmo modo que as simpatizantes, estabeleceram seu primeiro relacionamento com uma mulher intramuros, mas se assumem como "entendidas" depois disso.

Os trânsitos das mulheres entre afetos, desejos $e$ sexualidades emergem justamente como resposta as tramas das relações de poder que configuram esses contextos, tais como: à dificuldade na continuidade ou estabelecimento de relações heterossexuais uma vez presas, pelas exigências institucionais para as visitas intimas ou pelo abandono dos parceiros; à extrema pobreza afetiva da vida prisional; $e$, à intermitência ou ruptura das relações significativas cotidianas com o mundo de fora. Somado

${ }^{16}$ Entrevista, PFDF, jun./2004. 
às trajetórias e experiências afetivas e sexuais, para muitas violentas e conflitivas, antes de serem presas.

Com esses exemplos, quero mostrar que, junto com a produção normativa de gênero, as tecnologias também são produzidas pelas auto cadernos pagu (51), Dossiê Gênero e Estado: Formas de gestão, práticas e representações, Campinas, Núcleo de Estudos de Gênero-Pagu 2017-representações de gênero realizadas pelos sujeitos, agindo como tecnologias de agência, resistência, adaptação e sobrevivência. As tecnologias de gênero como representação e auto-representação, retomando a Lauretis (1994), implicam um movimento de vaivém entre a representação normativa do gênero e o que essa representação exclui, quer dizer, seu excesso, os pontos cegos, ou space-off de suas representações, conceito que apropria da teoria do cinema. As construções subversivas das identidades sexuais e de gênero atrás das grades desvelam esse outro lugar desses discursos, "esses outros espaços tanto sociais quanto discursivos que existem e se recriam nas margens, nas entrelinhas ou ao revés dos discursos hegemônicos e nos interstícios das instituições, rompendo ou desestabilizando qualquer representação (1994). A ideia de space off que Lauretis traz, resulta útil para compreender desde as margens das prisões como as identidades sociais são produzidas pelas relações e redes de poder e pelos contextos nos quais os sujeitos estão imersos. Nesse sentido, não se é um gênero, porque gênero é a própria linguagem possível por meio da qual se faz representatividade, instituição e poder.

Numa direção semelhante, Buttler (2002) pensa o gênero como mecanismo segundo o qual, se produzem e naturalizam noções do feminino e masculino, mas também como um poderoso dispositivo mediante $\mathrm{o}$ qual esses termos podem ser descontruídos. Nesse sentido, gênero é uma atividade, um fazer que é performado para alguém (real ou imaginário) e que produz efeitos relacionais, portanto, é contextual, contingente e dinâmico, revelando como o campo semântico de gênero não se esgota em categorias fechadas e binarias, e como as performatividades subversivas de gênero no nível micro das relações entre as pessoas 
presas atuam enquanto mecanismos de agencia, resistência $e$, muitas vezes, sobrevivência para a população presa. Nas prisões, retomando a Davis (2003), se produz e reproduz um mundo social que pode ser interpretado através e ao revés das fronteiras das nações-Estados, raças, gêneros e sexualidades (Davis, 2003).

\section{Comentários finais}

Ao longo destas páginas, trouxe uma reflexão sobre gênero e etnografia que decorreu de minha experiência de campo dentro de algumas prisões brasileiras. Analisei, particularmente, como o gênero, entendido enquanto complexa tecnologia de poder e em articulação com outras categorias de diferenciação como raça, classe e nacionalidade, opera e se desdobra em três dimensões $e$ escalas heterogêneas em relação às prisões $e$ ao fazer etnográfico em prisões.

Procurei demonstrar a centralidade do gênero na produção e compreensão do castigo estatal, da instituição penitenciária, das políticas criminais e dos dispositivos estatais intramurais, evidente no seu caráter fortemente generificado como masculino. As prisões, entendidas como parte do aparelho dos dispositivos estatais de segurança e de governo das populações, representam $e$ exemplificam o duplo fazer entre os processos e normatividades de Estado e de gênero que se (re)produzem e coproduzem numa relação de mutua constituição. O caráter generificado do castigo estatal, inscrito no emaranhado de outros dispositivos $e$ tecnologias de poder como a raça e a classe, se expressa de maneiras mais veementes em prisões que ocupam as margens do dispositivo carcerário, como as unidades prisionais femininas e as APACs, reproduzindo, no caso das primeiras, desigualdades estruturais num grupo significativo de mulheres (não brancas $e$ pobres), as quais sofrem de maneiras reais e diferenciadas tanto a criminalização dos seus corpos como os processos de aprisionamento, e que estão sobre representadas nas paisagens carcerárias. 
Na segunda aproximação, de caráter metodológico, analisei as tecnologias de gênero como vetores fundamentais que atravessaram $e$ articularam as inserções e a produção do trabalho de campo. Explorei a influência do gênero como determinante na produção das "zonas de contato": nos acessos, trânsitos, na configuração dos vínculos e estatutos relacionais com as diversas instituições penais, na construção das relações, posições $e$ situações com os diversos atores durante o campo, sinalizando os limites e as possibilidades do lugar situado, parcial e marcado por gênero, desde onde o trabalho de campo e o conhecimento etnográfico é produzido. Assim, sempre e em toda etnografia, haverão aspectos que permanecerão na sombra, ocultos, impenetráveis (Drake, 2015:165).

Terceiro, indaguei desde as micropolíticas da vida cotidiana intramuros e da dimensão das auto- representações subjetivas, dos space off das representações normativas, como as tecnologias de gênero também operam enquanto dispositivos de resistência, subversão e agência para a população privada da liberdade.

Para finalizar, resta dizer que, atualmente, não é possível realizar pesquisas etnográficas sobre as prisões sem articular gênero como dispositivo analítico e metodológico. Até pouco tempo atrás (pouco menos de 20 anos), existia uma agenda de pesquisa etnográfica mais gênerocentrica (Cunha, 2014) que responde à legitimidade que têm ganhando as etnografias das prisões dentro da própria disciplina e que, certamente, tem contribuído a ampliar o espectro teórico e analítico dos estudos prisionais, bem como a situar os debates sobre as prisões em outras chaves. Ao mesmo tempo, têm aberto o caminho a pesquisas $e$ estudos etnográficos sobre masculinidades $e$ feminidades não hegemônicas e identidades de género diversas, os quais tem cobrado relevância nos últimos anos (Shifter, 1997; Boldrin, 2015; Ferreira, 2015; Zamboni, 2017). Finalmente, tem promovido e refinando os debates $e$ aproximações teóricas $e$ metodológicas sobre raça/etnicidade, classe $e$ as complexas intersecções entre elas $e$ sem as quais, não seria possível compreender nem o gênero, nem as prisões, nem a etnografia. 


\section{Referências bibliográficas}

AlmedA, Di Nella. Mujeres y Cárceles en América Latina. Perspectivas Críticas y Feministas. Papers. Revista de Sociología (102), Barcelona, 2017, pp.183-214.

ALVES, Enedina do Amparo. Rés negras, judiciário branco: uma análise da interseccionalidade de gênero, raça e classe na produção da punição em uma prisão paulistana. Dissertação (Mestrado em Ciências Sociais), Pontifícia Universidade Católica de São Paulo PUC-SP, 2015.

Amigot, Patricia; PuJAL, Margot. Una lectura del género como dispositivo de poder. Sociológica, (70). Ciudad de México, 2009, pp.115-152.

ANDRADE, Bruna Soares Angotti Batista de. Entre as Leis da Ciência do Estado e de Deus: O surgimento dos presídios femininos no Brasil. Dissertação (Mestrado em Antropologia Social), Faculdade de Filosofia Letras e Ciências Humanas, Universidade de São Paulo, 2011.

ANIYAR DE CASTRO, Lolita. Las mujeres infractoras. Impacto y amplificación de los efectos de la pena. Capítulo Criminológico (304), Macaibo, 2002, pp.333-351.

ANTHONY, Carmen. Mujeres Invisibles: Las cárceles de mujeres en América Latina. Nueva Sociedad, n²08, 2007, pp.73-85.

BOLDRIN, Guilherme. Monas, envolvidos e o crime: etnografia com travestis e homossexuais em uma prisão paulista. Monografia, UFSCAR, 2015.

BuTLER, Judith. Undoing Gender. New York, Routledge, 2002.

CARR, Lucy. Re-entry to Prison: Transition from HMP Researcher to 'Independent' Researcher. In: DRAKE; EARlE; SlOAN (ed.). The Palgrave Handbook of Prison Ethnography. Basingstoke, Palgrave Macmillan, 2015, pp.199-213.

CLIFFORD, James. Prácticas espaciales: el trabajo de campo, el viaje y la disciplina de la antropología. En: Itinerarios transculturales. Barcelona, Gedesia, 1999, pp.71-100. 
CunHA, Manuela. A Prisão Segundo o Gênero. In: MoREIRA, Anabela (org.). Educar o Outro: as questóes de Gênero, dos Direitos Humanos $e$ da Educação nas Prisóes Portuguesas. Lisboa, Publicações Humanas, 2007, pp.81-87.

CunHA, Manuela. The Ethnography of Prisons and Penal Confinement. Annual Review of Anthropology (43), Palo Alto - CA, 2014, pp.217233.

DAVAR, Bhargavi. Women, Society and Mental Illness. In: Mental health from a gender perspective. Thousand Oaks, CA, Sage Publications; 2001.

DAVIS, Angela; DENT, Gina. A prisão como fronteira: uma conversa sobre gênero, globalização e punição. Revista Estudos Feministas 11(2), Florianópolis, 2003.

DAVIS, Angela. Como o gênero estrutura o sistema prisional. Em: Estarão obsoletas as prisóes? Rio de Janeiro, Difel, 2018.

LAGARDE, M. Los cautiverios de las mujeres, madresposas, monjas, putas, presas y locas. México DF. Universidad Nacional Autónoma de México, 2006.

LAURETIS, Teresa De. A tecnologia do gênero. In: HolandA, Heloísa Buarque de. Tendências e impasses: o feminismo como crítica da cultura. Rio de Janeiro, Iser, 1994, pp.206-241.

DRAKE, EARLE; SLOAN. General Introduction: What Ethnography tells us about prisons and what prisons tell us about ethnography? In: DRAKE, EARLE; SlOAN (ed.), The Palgrave Handbook of Prison Ethnography. Basingstoke, Palgrave Macmillan, 2015.

EARLE, Rod. About prison ethnography. In: DRAKE; EARLE; SlOAN (ed.). The Palgrave Handbook of Prison Ethnography. Basingstoke, Palgrave Macmillan, 2015.

FELTRAN, Gabriel. Fronteiras de tensão: politica e violência nas periferias de São Paulo. São Paulo: Editora Unesp: CEM: Cebrap, 2011.

FERREIRA, Guilherme. Travestis e Prisóes: Experiência social e mecanismos particulares de encarceramento. Curitiba, Multidéia, 2015. 
Foucault, Michel. Vigiar e Punir: nascimento da prisão. Petrópolis, Vozes, 2003 [1975].

Foucault, Michel. História da sexualidade I: A vontade de Saber. Rio de Janeiro, Edições Graal, 1985 [1979].

GoDoI, Rafael. Ao redor e através da prisão: cartografias do dispositivo carcerário contemporâneo. Dissertação (Mestrado em Sociologia), Sociologia, Universidade de São Paulo, 2010.

Goffman, Erving. Manicômios, Prisóes e Conventos. São Paulo, Editora Perspectiva, 2003.

HAMMERSLEY, Martyn. Research "Inside" Viewed from "Outside": Reflections on Prison Ethnography. In: DRAKE; EARLE; SLOAN (ed.). The Palgrave Handbook of Prison Ethnography. Basingstoke, Palgrave Macmillan, 2015.

MAllarT, Fabio. As cadeias dominadas. A Fundação CASA, suas dinâmicas e as trajetórias de jovens internos. São Paulo, Ed. Terceiro Nome, 2014.

MATSUE, Regina Yoshie; GOMES, Pedro. Quem se diferencia apanha (deru kui ha watareru): experiência etnográfica, afeto e antropologia no Japão. Mana (23-2), Rio de Janeiro, 2017.

MINISTÉRIO da Justiça e Segurança Pública. Relatório: Levantamento Nacional de Informações Penitenciárias. Brasília, 2014.

MINISTÉRIO da Justiça e Segurança Pública. Relatório: Levantamento Nacional de Informações Penitenciárias. Brasília, 2017 [https://drive.google.com/file/d/1xSdo30zU7sKgWIzSZbval6zUQAiLvbD/view - acesso em: 12 ago. 2018].

MoOLmAN, Benita. Ethnography: Exploring Methodological Nuances in Feminist Research with Men Incarcerated for Sexual Offences Benita Moolman. DRAKE; EARLE; SlOAN (ed.). The Palgrave Handbook of Prison Ethnography. Basingstoke: Palgrave Macmillan, 2015, pp.199213.

MusumUeSCI, Bárbara; ILGENFRITZ, Lara. Prisioneiras: vida y violência atrás das grades. Rio de Janeiro, Garamond, 2002.

ORDÓÑEZ-VARGAS, Laura. Mujeres Encarceladas: Proceso de Aprisionamiento en la Penitenciaría Femenina de Brasilia. Revista 
Universitas Humanística de la Facultad de Ciencias Sociales de la Pontificia Universidad Javeriana, n. 61, Ano XXXII, enero-junio, 2006, Bogotá, pp.183-200.

ORDÓÑEZ-VARGAS, Laura. É possível humanizar a vida atrás das grades?: Uma etnografia do Método APAC de gestão carcerária. Tese (Doutorado em Antropologia Social), Departamento de Antropologia, Universidade de Brasília, Brasília, 2011.

PADOVANI, Natália. Sobre casos e casamentos: Das redes de afetos e dos relacionamentos amorosos através das penitenciárias femininas das cidades de São Paulo e Barcelona. Tese (Doutorado em Antropologia Social), Instituto de Filosofia e Ciências Humanas, Universidade Estadual de Campinas, 2015 a.

PADOVANI, Natália. Pra (Re)Fazer Indiana Jones: crimes e caminhadas da antropólog(i)a nos processos de produção das "classes perigosas". Revista Interdisciplinar de Sociologia e Direito 17-(3), Niterói - RJ, 2015b, pp.115-134.

PADOVANI, Natália. Tráfico de mulheres nas portarias das prisões ou dispositivos de segurança e gênero nos processos de produção das "classes perigosas". cadernos pagu (51), Dossiê Gênero e Estado: Formas de gestão, práticas e representações, Campinas, Núcleo de Estudos de Gênero-Pagu, 2017.

PeIRANO, Mariza. Etnografia não é método. Horizontes Antropológicos 20 (42). Porto Alegre, 2014, pp.377-391.

PiACENTINI, Laura. "Get In, Get Out, Go Back?": Transitioning from Prison Ethnography to Prison Policy Research in Russia. In: DRAKE; EARLE; SlOAN (ed.). The Palgrave Handbook of Prison Ethnography. Basingstoke, Palgrave Macmillan, 2015.

PISCITElli, Adriana. Sexo tropical em um país europeu: migração de brasileiras para a Itália no marco do "turismo sexual" internacional. Revista Estudos Feministas, 15 (3), Florianópolis, 2007, pp.717-774.

PrATT, Mary. Arts of the Contact Zone. Profession, New York, 1991, pp.33 - 40.

RamalHo, José Ricardo. A ordem do crime o mundo pelo avesso. Rio de Janeiro, Graal, 1979. 
RHODES, Lorna A. Toward an Anthropology of Prisons. Annual Review of Anthropology (30), Palo Alto - CA, 2001, pp.65-83.

VIANNA, Adriana; LowENKRON, Laura. O duplo fazer do gênero e do Estado: Interconexões, materialidades e linguagens. cadernos pagu (51), Dossiê Gênero e Estado: Formas de gestão, práticas e representações. Campinas, Núcleo de Estudos de Gênero-Pagu, 2017.

WACQUANT, Loïc. The Curious Eclipse of Prison Ethnography in the Age of Mass Incarceration. Sage Publications, vol. 3(4), 2002, pp.371-397 [http://eth.sagepub.com/cgi/content/abstract/3/4/371].

Wagner, Roy. A Invenção da Cultura. São Paulo, Cosac Naify, 2010.

WALDRAM, James. Challenges of Prison Ethnography. Anthropology News, vol. 50, Issue 1, 23 de janeiro de 2009, pp.4-5 [http://www3.interscience.wiley.com/cgibin/fulltext/121660489/PDFSTART].

WolA. Women, Drug Policies and Incarceration. A Guide for Policy Reform in Latin America and the Caribbean. De justiça e direitos humanos. [http://www.oas.org/en/cim/docs/womendrugsincarceration-en.pdf access on 22 jun. 18].

ZAMBONI, Marcio. O barraco das monas na cadeia das coisas: notas etnográficas sobre a diversidade sexual e de gênero no sistema penitenciário. Aracê - Direitos Humanos em Revista, n. 5, 2017. 